\title{
Strategi Pengembangan Usaha Rumah Tangga di Pantai Cemara Banyuwangi (Studi Kasus Usaha Ibu Rumah Tangga KUB Pantai Rejo)
}

\section{Household Business Development Strategy in Cemara Beach Banyuwangi (Case Study of Housewives' Business KUB Pantai Rejo)}

\author{
Elok Rosyidah $^{1}$, Sahru Romadloni ${ }^{2}$ \\ Program Studi Manajemen, Fakultas Ekonmi, Universitas 17 Agustus 1945 Banyuwangi, Jalan Adi \\ Sucipto No 26, Banyuwangi, Jawa Timur, Indonesia. \\ Program Studi Pendidikan Sejarah, Fakultas Keguruan dan Ilmu Pendidikan, Universitas 17 Agustus \\ 1945 Banyuwangi, Jalan Adi Sucipto No 26, Banyuwangi, Jawa Timur, Indonesia. \\ Email: elok.rosyi@gmail.com
}

\begin{abstract}
Abstrak
Hutan mangrov merupakan salah stau ekosistem khas pesisir yang mempunyai fungsi dan peran penting bagi kelanjutan kawasan pesisir. Dilingkungan pesisir, hutan mangrove menjadi sumberdaya alam penting yang memiliki tiga fungsi utama yaitu fungsi fisik, fungsi biologis dan fungsi ekonomis. Fungsi ekonomis yang dihasilkan adanya hutan mangrov dimanfaatkan oleh Kelompok Usaha Bersama (KUB) Pantai Rejo khususnya Kelompok Wanita. Salah satunya adalah membuat kerupuk pangsit berbahan dasar daun mangrove dan membuat sirup berbahan dasar biji buah mangrove. Permasalahan yang dihadapi oleh KUB Pantai Rejo adalah perizinan produk/usaha, permodalan, pemasaran. Tujuan dalam penelitian ini adalah untuk memberikan strategi pengembangan industri rumah tangga pantai cemara banyuwangi. Jenis penelitian yang digunakan dalam penelitian ini bersifat dekriptif kualitatif menggunakan pendekatan studi pustaka dan studi lapang. Memberikan faktor pendorong sebagai upaya pengembangan usaha yaitu adanya keterlibatan pemerintah dan pihak terkait, akses permodalan yang mudah, pendampingan untuk melakukan legalitas usaha (PIRT), pelatihan dan pengembangan dengan strategi pemasaran dan promosi online.

Kata Kunci: Strategi Pengembangan Usaha, Pantai Cemara, dan Mangrove.
\end{abstract}

\begin{abstract}
Mangroves are one of the typical coastal ecosystems that have important functions and roles for the continuation of coastal areas. In the coastal environment, mangrove forests are important natural resources that have three main functions, namely physical functions, biological functions and economic functions. The economic function generated by the mangrove forest is utilized by the Joint Business Group (KUB) of Pantai Rejo, especially the Women's Group. One of them is making dumpling crackers made from mangrove leaves and making syrup made from mangrove fruit seeds. The problems faced by KUB Pantai Rejo are product/business licensing, capital, marketing. The purpose of this study is to provide a strategy for the development of the banyuwangi pine beach household industry. The type of research used in this research is descriptive qualitative using a literature study and field study approach. Providing driving factors as a business development effort, namely the involvement of the government and related parties, easy access to capital, assistance to conduct business legality (PIRT), training and development with marketing strategies and online promotions.
\end{abstract}

Keywords: Business Development Strategy, Cemara Beach, and Mangroves. 


\section{PENDAHULUAN}

Indonesia merupakan negara kepulauan dihadapkan problematika abrasi atau yang disebut erosi pantai. Fenomena abrasi pantai yang terjadi terus menerus disekitar wilayah maritim. Kabupaten Banyuwangi daratan pesisirnya semakin tahun kian terkikis abrasi. Banyuwangi merupakan wilayah maritim yang perlu diadakan reboisasi untuk mengatasi masalah pergeseran pantai. Pantai Cemara Banyuwangi salah satu pantai yang terkena abrasi, sebanyak 1.200 pohon cemara tumbang. Pantai cemara yang berhadapan langsung dengan pulau Bali telah berhasil menanam sekitar 19000 pohon cemara udang (Casuarina Equisetifolia) dengan luas 10,2 hektar (Rifaldi, 2018).

Konservasi mangrov di pantai cemara sudah dilakukan sejak tahun 2019. Sekitar 5 hektar yang ditanami sepanjang sungai dan muara. Konservasi mangrove menjadi salah satu tambahan destinasi baru tentang destinasi wisata edukasi yang sebelumnya sudah ada destinasi konservasi penyu jenis lepidochelys olivacea (penyu lekang) (Amalia, 2018).
Hutan mangrov merupakan salah stau ekosistem khas pesisir yang mempunyai fungsi dan peran penting bagi kelanjutan kawasan pesisir. Dilingkungan pesisir, hutan mangrove menjadi sumberdaya alam penting yang memiliki tiga fungsi utama yaitu fungsi fisik, fungsi biologis dan fungsi ekonomis. Hutan mangrov yang memiliki fungsi perlindungan fisik untuk menjaga stabilitas garis pantai pengendali naiknya batas antara permukaan air tanah dengan permukaain air laut kearah daratan, fungsi biologis memiliki manfaat salah satunya sebagai mencari makan bagi ikan dan biota laut lainnya. Fungsi ekonomis dari hutan mangrove adalah penghaisl kayu untuk bahan baku dan bahan bangunan, bahan makanan dan obat-obatan (Nizar, 2018).

Fungsi ekonomis yang dihasilkan adanya hutan mangrove dimanfaatkan oleh Kelompok Usaha Bersama (KUB) Pantai Rejo khususnya Kelompok Wanita. Salah satunya adalah membuat kerupuk pangsit berbahan dasar daun mangrove dan membuat sirup berbahan dasar biji buah mangrove. Industri rumah tangga adalah sebuah aktivitas usaha pengolahan bahan mentah menjadi barang jadi yang 
memiliki nilai tambah dalam rangka mendapatkan keuntungan atau laba. Industri ini masuk kategori jenis industri ekstraktif yaitu industri yang berbahan bakunya berasal dari alam sekitar (Wahyukinasih, 2014).

Pengembangan usaha harus dilakukan karena potensi jual produk yang memiliki manfaat tinggi dari bahan dasar ekstrak mangrove yaitu daun dan biji buahnya. Produk yang dibuat oleh Ibu Rumah Tangga KUB Pantai Rejo selama ini dipasarkan di warung-warung yang tersedia di lokasi wisata tersebut, padahal produk tersebut bisa dikembangkan menjadi bisnis yang besar, dengan melakukan strategi pemasaran yang tepat akan menjangkau pasar yang lebih luas dan modern serta menambah kuantitas penjualan. Memperhatikan aspek legalitas produk jika ingin mengembangkan produk. Legalitas usaha merupakan standar yang harus dipenuhi oleh pelaku usaha. Pelaku usaha dituntut untuk memenuhi persyaratan tersebut agar dapat bersaing di era pasar bebas (Kusmanto, 2019). Menurut maulida (2017) presentase kesulitan yang dihadapi oleh pelaku UMKM yang paling dominan adalah faktor permodalan dan pemasaran.
Tujuan dalam penelitian ini adalah untuk memberikan Strategi Pengembangan Industri Rumah Tangga Pantai Cemara Banyuwangi (Studi Kasus Usaha Ibu-Ibu KUB Pantairejo).

\section{METODE PENELITIAN}

Metode yang digunakan dalam penelitian ini adalah memberikan gambaran tentang Strategi Pengembangan Industri Rumah Tangga di Pantai Cemara Banyuwangi. Jenis penelitian yang digunakan dalam penelitian ini bersifat dekriptif kualitatif menggunakan pendekatan studi pustaka dan studi lapang (Lexy J. Moleong, 2019). Tahapan penelitian dilaksanakan dengan menghimpun beberapa sumber diantaranya:

a. Observasi, melakukan pengamatan secara lansgung untuk memperoleh gambaran yang jelas mengenai objek yang diteliti.

b. Sumber kepustakaan, pengumpulan data melalui sumber kepustakaan bertujuan untuk menggali informasi sebanyak mungkin mengenai objek serta elemen-elemen yang terkait dalam penelitian.

c. Wawancara, mengumpulkan data dengan cara mengadakan tanya jawab secara langsung dengan 
pihak yang berkepentingan dan berkaitan dengan objek peneliti.

\section{HASIL DAN PEMBAHASAN}

Hutan mangrove di kawasan pantai cemara yang dimanfaatkan oleh Ibu Rumah Tangga KUB Pantai Rejo adalah daun jeruju (Acanthus ilicifus) dan buah pidada (Sonneratia caseolaris). Produk yang dihasilkan dari pengolahan yang menggunakan bahan baku daun jeruju yaitu pangsit sedangkan buah pidada menghasilkan sirup. Strategi pengembangan industri rumah tangga yang perlu dilakukan adalah dengan menganalisisis kesulitan yang dialami oleh pelaku usaha (Hidayat \& Irdiana, 2018).

Aspek keuangan/financial meliputi kondisi keuangan yang ada dalam industri rumah tangga tersebut yang meliputi modal awal sampai kondisi keuangan perusahaan saat ini. Menurut Muhyi (2021) keuangan atau kesulitan modal menjadi salah satu faktor penghambat pengembangan produk. Karena kondisi ekonomi yang pas-pasan dan juga karena adanya pandemi Covid-19 mengakibatkan pendapatan semakin menurun.

Salah satu tindakan yang perlu dilakukan untuk meyampaikan produk dari tangan produsen ke konsumen adalah dengan memasarkannya. Kegiatan pemasaran bisa dilakukan secara lansgung maupun tidak langsung. Menurut Muhyi

ketidakmampuan mengoperasikan dan mengikuti perkembangan teknologi menjadi salah satu kendala dalam memasarkan produk. Menurut Ashariyadi (2016) UMKM di Indonesia mengalami kesulitan dalam persaingan usaha dikarenakan lemahnya kegiatan branding dan promosi serta penetrasi pasar di luar negeri.

Diperlukan solusi untuk mengatasi permasalah diatas dengan menerapkan beberapa faktor pendorong diantaranya:

a. Peran pemerintah sangat dibutuhkan dalam mengatasi permasalah yang dihadapai oleh pelaku usaha atau UMKM. Kebijakan pemerintah yang dikeluarkan akan mempengaruhi pengembangan dunia usaha seperti Undang-Undang mendukung pengembangan usaha. Pemerintah Kabupaten melalui penetapan Peraturan Daerah atau Peraturan Bupati mendirikan sebuah institusi untuk menjamin pinjaman yang diberikan untuk membiayai usaha kecil (Saymeh, 2014). 
b. Memberikan akses permodalan yang mudah serta bunga yang rendah menjadi salah satu solusi untuk mengatasi masalah diatas. Proses aplikasi pinjaman yang mudah bagi pelaku usaha UMKM menjadi penting karena tidak kesulitan dalam pengajuan pinjaman karena jumlah dokumentasi yang diperlukan sangat banyak dan proses persetujuan yang panjang. Menargetkan sedikitnya 50 persen pelaku UMKM yang memenuhi syarat kelayakan dengan memberikan pinjaman atau bantuan pendanaan dengan modal rendah (Alaudin, 2015).

c. Perizinan usaha atau Legalitas usaha mikro dan kecil (UMK) melalui perizinan sangat penting pelaku usaha untuk dapat mengakses permodalan dalam mengembangkan usahanya dan bersaing dengan produk barang dan jasa dari dalam dan luar negeri (Suhayati, 2016). Menurut Sukoco (2019) pentingnya legalitas usaha atau perizinan usaha memberikan peluang yang sangat kuat bagi pelaku UMKM untuk mendapatkan berbagai skim bantuan dari pemerintah dan juga mempermudah memasarkan produk ke pasar ritel modern. Pemberian informasi dan pendampingan terkait prosedur dan persyaratan perizinan usaha diharapkan mampu memberikan dorongan agar produk bisa ber PIRT.

d. Memberikan pelatihan dan pengembangan kepada Ibu Rumah Tangga KUB Pantai Rejo agar semakin terampil dalam mengelola industri rumah tangga. Keterampilan SDM juga mempengaruhi kualitas dan kuantitas produk (Fatria, 2017). Memberikan pelatihan tentang strategi pemasaran dan promosi. Diera digitalisai yang modern saat ini strategi pemasaran online menjadi salah satu pilihan utama dalam mempromosikan produknya. Pemanfaatan sosial media menjadi strategis karena mampu mempermudah proses promosi dan memperluas dampak dari pemasaran produk serta proses pengenalan produk semakin cepat.

\section{KESIMPULAN}

Strategi pengembangan industri rumah tangga menjadi penting untuk 
dilakukan

dalam

upaya

mengembangkan produk pangsit dan sirup yang dibuat oleh Ibu Rumah Tangga KUB Pantai Rejo. Lemahnya permodalan dan rendahnya pegetahuan tentang strategi pemasaran. Selain itu, Ibu Rumah Tangga KUB Pantai Rejo masih kurang memahami prosedur dan persyaratan perizianan usaha. Hal ini menjadi peluang bagi pemerintah atau pihak-pihak terkait untuk memberikan pelatihan dan pengembangan usaha kepada Ibu Rumah Tangga KUB Pantairejo.

\section{Ucapan Terima Kasih}

Terimkasih kami ucapkan kepada Allah SWT. Yang telah memberikan ilmu dan pengetahuan sehingga bisa terselesaikannya paper ini. Seluruh pihak yang telah membantu memberikan informasi.

\section{Daftar Pustaka}

Alauddin and Mustafa Manir Chowdhury. 2015. Small and Medium Enterprise in Bangladesh-Prospects and Challenges. Global Journal of Management and Business Research: C Finance Volume 15 Issue 7 Version 1.0 Year 2015 Global Journals Inc. (USA). Online ISSN: 2249-4588 \& Print ISSN: 09755853.

Amali, Firda Racham, et Al. (2018). Pemetaan dan Peningkatan Kualitas Layanan Jasa Wisata Pantai Cemara Banyuwangi. Journal of Tourism Creativity. Program

Manajemen Bisnis Pariwisata. Politeknik Negeri Banyuwangi.

Arifah, Tutik. (2011). Strategi Pengembangan Industri Kecil jamur Tiram di Kecamatan Jambu, Kabupaten Semarang. Jurnal Ekonomi Pembangunan Fakultas Ekonomi Universitas Negeri Semarang.

Fatria, Muhammad Akbar. (2017). Strategi Pengembangan Industri Rumah Tangga Di Kota Pekanbaru (Studi Kasus Usaha Jamur Crispy Industri Pengolahan Jamur Krispi). JOM Fekon, Vol. 4 No 1 (Februari). 
Journal of Aquaculture Science

DOI: https://doi.org/10.31093/joas.v6i1IS.161

Hidayat, Z., \& Irdiana, S. (2018). Pkm Inovasi Produk Olahan Jamur Tiram Di Kecamatan Kedungjajang Kabupaten Lumajang. Empowerment Society. https://doi.org/10.30741/eps.v1i02.307

Kusmanto, Heri, et Al. (2019). Pentingnya legalitas Usaha Bagi Usaha Mikro Kecil dan Menengah. JUPIIS: Jurnal Pendidikan Ilmu-ilmu Soial. ISSN 24077429 (Online).

Lexy J. Moleong, D. M.A. (2019). Metodologi Penelitian Kuantitatif (Edisi Revisi), Pt. Remaja Rosda Karya. Doi: 10.1016/J. Carbpol. 2013.02.055.

Nisa, Khorun, et Al. (2018). Strategi pemasaran online dan offline. Jurnal Abdikarya: Jurnal Karya Pengabdian Dosen dan Mahasiswa Vol 01 No 1 (Februari). EISSN: 2655-9706.

Nizar, Muhammad, et Al. (2018). Pengembangan Potensi Lokal Melalui Pemberdayaan Lingkungan dan UMKM pada Masyarakat Pesisir.

Rifaldi, Muhammad. (2018) Dinamika Sistem Pengelolaan Ekowisata Pantai Cemara Dan Konservasi Penyu Lekang (Lepidochelys Olivacea) Di Pantai
July 2021 Vol 6 Issue Spesial: 90-96

Online pada http://joas.co.id

Cemara Kabupaten Banyuwangi Provisnsi Jawa Timur. Sarjana thesis, Universitas Brawijaya.

Saymeh, Abdul Aziz, et Al. (2014). Assessment of Small Enterprise Financing, Case of Jordan. Global Journal of Management and Business Research: C Finance Volume 14 Issue 2 Version 1.0 Year 2014 Publisher: Global Journals Inc. (USA). Online ISSN: 2249-4588 \& Print ISSN: 0975-5853.

Suhayati, Monika. (2016). Penyederhanaan Izin Usaha Bagi Pelaku Usaha Mikro Dan Kecil Dari Perspektif Hukum: Studi Di Provinsi Daerah Istimewa Yogyakarta (Simplification Of Business Licensing For Micro And Small Interprises). Pusat penelitian Badan Keahlian DPR RI.

Wahyukinasih, Mayang Haris. Et Al. (2014). Analisis Kelayakan Berbasis Hasil Hutan Bukan Kayu Ekosistem Mangrove Di Desa Margasari lampung Timur. Jurnal Sylva Lestari. ISSN 2339-0913.

\section{Sumber Wawancara:}

Muhyi. (2021). Wawancara Usaha Pangsit dan Sirup Mangrove. Ketua KUB Pantai rejo Pantai Cemara. 60 Menit. Banyuwangi. 